\title{
Influence of geometrical parameters on the splitting forces in textile-reinforced concrete
}

\author{
Philipp Preinstorfer - Benjamin Kromoser
}

Received: 14 April 2020/Accepted: 20 November 2020/Published online: 11 December 2020

(C) The Author(s) 2020

\begin{abstract}
Splitting forces due to bond action can lead to the premature failure of reinforced concrete structural components. In earlier research it was mentioned that it is mainly geometrical parameters that play a key role in the distribution and magnitude of the splitting forces in textile-reinforced concrete. However, so far no accurate geometrical characterisation of textile reinforcement has been performed which considers all the relevant properties of the material such as the regularly repeating variation in cross-sectional dimensions. In this paper, four geometrical parameters are introduced which permit a clear geometrical characterisation of fibre strands and allow for the comparison of different types of textile reinforcement. Furthermore, a broad parametric study was carried out for a pull-out test in which the parameters were varied, and the influence of these parameters on the splitting forces occurring in textilereinforced concrete was visualised. Based on this parametric study, a mechanical model was established, which takes into account experimental data from previous research. This model allows for the
\end{abstract}

P. Preinstorfer $(\square)$

Institute of Structural Engineering, TU Wien, Karlsplatz

13, E212-2, 1040 Vienna, Austria

e-mail: philipp.preinstorfer@tuwien.ac.at

B. Kromoser

Institute of Structural Engineering, University of Natural

Resources and Life Sciences, Peter-Jordan-Straße 82,

1190 Vienna, Austria calculation of the splitting forces occurring in textilereinforced concrete when one short fibre strand is pulled out of the concrete.

Keywords Textile-reinforced concrete .

Splitting force - Longitudinal cracking .

Geometrical characterisation · Parametric study

\section{List of symbols}

$a, b(\mathrm{~mm}) \quad$ Ellipse axis, where $a>b$

$A_{\mathrm{kr}}\left(\mathrm{mm}^{2}\right) \quad$ Area of a circle

$A_{\mathrm{r}}\left(\mathrm{mm}^{2}\right) \quad$ Cross-sectional area of the fibre strand

$A_{\mathrm{r}, \mathrm{F}} \quad$ Local maxima of the cross-sectional

$\left(\mathrm{mm}^{2}\right) \quad$ area of the fibre strand

$A_{\mathrm{r}, \mathrm{K}} \quad$ Local minima of the cross-sectional

$\left(\mathrm{mm}^{2}\right) \quad$ area of the fibre strand

$b_{\mathrm{r}, \mathrm{F}}(\mathrm{mm}) \quad$ Local maxima of the width of the fibre strand

$b_{\mathrm{r}, \mathrm{K}}(\mathrm{mm}) \quad$ Local minima of the width of the fibre strand

$d_{\mathrm{r}, \mathrm{F}}(\mathrm{mm})$ Local maxima of the thickness of the fibre strand

$d_{\mathrm{r}, \mathrm{K}}(\mathrm{mm})$ Local minima of the thickness of the fibre strand

$e(\mathrm{~mm}) \quad$ Centre-to-centre distance between the transverse fibre strands

$E_{\|} \quad(\mathrm{kN} /$ Young's modulus in the longitudinal $\mathrm{mm}^{2}$ ) direction

$E \perp \quad(\mathrm{kN} /$ Young's modulus in the transverse $\mathrm{mm}^{2}$ ) direction 
$f(\mathrm{~mm}) \quad$ Deflection of the section of a longitudinal fibre strand between its intersections with two adjacent transverse fibre strands

$F_{\mathrm{c}}(\mathrm{N}) \quad$ Concrete compression strut

$f_{\mathrm{cm}} \quad$ (N/ Mean value of the concrete compression $\left.\mathrm{mm}^{2}\right) \quad$ strength

$f_{\text {ctm }}$ (N/ Mean value of the concrete tensile $\mathrm{mm}^{2}$ ) strength

$F_{\text {sp,y }}(\mathrm{N}) \quad$ Splitting force in the $y$-direction

$F_{\mathrm{sp}, \mathrm{z}}(\mathrm{N}) \quad$ Splitting force in the $z$-direction

$F_{\mathrm{x}}(\mathrm{N}) \quad$ Tensile force in the longitudinal fibre strand

$G_{\|} \quad(\mathrm{kN} /$ Shear modulus in the 12- and $\mathrm{mm}^{2}$ ) 13-directions

$G_{\mathrm{f}} \quad(\mathrm{N} / \quad$ Shear modulus

$\mathrm{mm})$

$k_{\mathrm{A}}$

Parameter to describe the influence of the magnitude of the cross-sectional expansion

$K_{\mathrm{c}} \quad$ Shape factor to describe the fractured surface

$k_{\mathrm{F}} \quad$ Parameter to describe the influence of the cross-section geometry

$k_{\mathrm{p}} \quad$ Parameter to describe the influence of the dominant direction of the crosssectional expansion

$K_{\mathrm{TT}} \quad(\mathrm{N} / \quad$ Interface stiffness $\mathrm{mm}^{3}$ )

$k_{\mathrm{W}}$

$U_{\mathrm{kr}}(\mathrm{mm}) \quad$ Circumference of a circle with the same area as a stipulated fibre strand

$U_{\mathrm{r}}(\mathrm{mm}) \quad$ Circumference of the fibre strand

$u_{\mathrm{x}, \mathrm{A}}(\mathrm{mm}) \quad$ Slip

口 Parameter to describe the function of damage evolution

$\square_{F} \quad$ Parameter to take into account the influence of the cross-section geometry of the fibre strand

$\square_{\mathrm{m}}^{0}(\mathrm{~mm}) \quad$ Displacement at which cohesion damage initiates

$\square_{\mathrm{m}}^{\mathrm{f}}(\mathrm{mm}) \quad$ Displacement at which total cohesion damage occurs

口 Parameter to describe the eccentricity

$\square_{\mathrm{c} 1} \quad(\mathrm{~mm} / \quad$ Strain in the concrete under maximum

m) compressive stress
$\mathrm{Q}_{\mathrm{cu}} \quad(\mathrm{mm} / \quad$ Breaking strain of concrete

m)

$\square\left({ }^{\circ}\right) \quad$ Inclination of the concrete compression strut

口 Friction

$\square_{\|} \quad$ Transverse strain in the 12- and 23-directions

Transverse strain in the 23-direction

$\square_{\mathrm{b} 0} \quad$ (N/ Concrete compressive strength under $\left.\mathrm{mm}^{2}\right) \quad$ biaxial loading

$\mathrm{Q}_{\mathrm{c} 0} \quad$ (N/ Concrete compressive strength under $\mathrm{mm}^{2}$ ) uniaxial loading

प ( $\left.{ }^{\circ}\right) \quad$ Inclination of the splitting force with respect to the plane perpendicular to the longitudinal axis of the fibre strand

प ( $\left.{ }^{\circ}\right) \quad$ Angle of dilatancy

\section{Indices}

kr Circle

r Fibre strand

F Location in the longitudinal fibre strand halfway between the intersections of two adjacent transverse fibre strands

$\mathrm{K}$ Location in the longitudinal fibre strand at the intersection with a transverse fibre

\section{Introduction}

Textile reinforcement is a composite material consisting of bundled high-performance filaments. These bundles are called rovings if the filaments are straight and not twisted. The rovings are processed to form a mesh, and the state of the art nowadays is to impregnate the mesh with special resins or polymers to improve the inner bond properties of the rovings $[1,2]$. The mesh is used as reinforcement in concrete and exhibits advantageous material properties. The tensile strength of carbon fibre strands, for example, can be as high as $3000 \mathrm{MPa}$ and, in the newest generation of textile reinforcement, even higher [3]. Another huge benefit is the low risk of corrosion (for carbon filaments there is no risk of corrosion at all), allowing the design engineer to reduce the concrete cover to a minimum.

Considering these two advantages, high strength and superior durability, various applications of this type of structural concrete become possible. One of the first successful applications of textile-reinforced 
concrete is described by Helbig et al. [4] - a lightweight footbridge constructed in 2017 which was exclusively reinforced with textile reinforcement. The potential of this high-performance composite material is also high for the production of filigree shell structures [5, 6], as textile reinforcement coated with a stiff impregnation material can easily be formed into the desired shape during the production process, or, if a flexible impregnation material is used, the reinforcement can be brought into the desired shape directly at the construction site. This opens new possibilities for the design of free-form structural components exhibiting advantageous loadcarrying mechanisms and for the strengthening of existing structures [7-9].

The usage of textile-reinforced concrete in the previously described areas of application permits a crucial reduction in overall material needed [10]. In these times of climate crisis, the concrete industry is expected to find innovative solutions to reduce the environmental impact of the industry as a whole, as the production of cement is responsible for about $6 \%$ of the carbon emissions generated worldwide (and still increasing) [11]. The results of calculations performed by Stoiber et al. [12] indicate that a reduction in the embodied $\mathrm{CO}_{2}$ can be achieved by using textile-reinforced concrete.

Recognising the great potential of textile-reinforced concrete, researchers at the Institute of Structural Engineering at TU Wien launched a research project in 2015, with a focus on sustainable construction using textile-reinforced concrete. The overarching aim of the project was to scientifically investigate the sustainability potential of textilereinforced concrete. In experimental investigations carried out within this project, pronounced longitudinal cracking in the layer of textile reinforcement due to high bond forces was observed in several test specimens $[13,14]$. Similar behaviour had previously been observed by other researchers [15-17]. The longitudinal cracks led to the premature failure of the specimens, thus reducing the efficiency of the highperformance reinforcement. In order to render textile reinforcement advantageous both ecologically and economically, this type of failure has to be avoided, so that the full potential of textile-reinforced concrete can be exploited. Therefore it is necessary to understand the mechanisms which lead to the aforementioned cracking behaviour. Preinstorfer et al. carried out investigations on the topic and concluded that it is mostly certain geometric characteristics of the fibre strand that determine the distribution of the splitting forces and their magnitude [18].

However, due to a wide range of variation in the production process of textile reinforcement, in terms of materials (both filaments and impregnation), yarn count, impregnation ratio, production method, and other parameters, a consistent description of the geometric characteristics of textile reinforcement is not available yet. In this paper, a description is given for specific geometric characteristics of the fibre strand which were identified as playing a major role in the distribution and magnitude of the splitting forces due to bond action. This allows for the comparison of different types of textile reinforcements as a function of these geometric characteristics. Based on this description a broad numerical parametric study was carried out. The aim of the study was to quantify the influence of the individual geometrical parameters on the splitting forces in the concrete (which lead to the aforementioned longitudinal cracking) occurring when one short fibre strand is pulled out of the concrete. Furthermore, in this paper a mechanical model is introduced which permits the calculation of the splitting forces in textile-reinforced concrete under the aforementioned boundary conditions (the pulling out of one short fibre strand).

\section{Methods and boundaries}

To characterise the geometry of the fibre strands, a completely new method is used in this paper. While in the past researchers tried to determine the cross section at certain points along the length of the fibre strand by cutting the fibre strand and measuring the cross-sectional dimensions (e.g. [19]), in this research an entirely optical measurement method was used. The fibre strands were scanned using a laser, and a digital 3D model was generated from the measurements, making it possible to examine the real geometry at a large scale (the whole procedure is explained in detail in Sect. 3.1). Based on the measurement results, four geometrical parameters are introduced, allowing for a clear geometrical description of the fibre strand in terms of the relevant characteristics which affect the splitting forces due to 
bond action. This permits their influence on the magnitude and distribution of the splitting forces to be estimated. These parameters also facilitate a comparison between different types of textile reinforcement with respect to the splitting forces.

In a subsequent parametric study, the geometrical parameters were varied over a wide range with the aim of visualising the influence of the geometry of the fibre strand on the splitting forces occurring in the concrete due to bond action. The underlying numerical model defined in Abaqus/CAE and used in the parametric study is described in Preinstorfer et al. [20] and was calibrated against the results of experimental investigations. The mechanical model, which is described in this paper, takes into account the results of the parametric study and of preliminary investigations carried out by the authors [18]. All the input parameters of the model are of a geometrical nature.

Preinstorfer et al. proposed a classification system for three types of textile reinforcement exhibiting significantly differing bond behaviour [21]. The reinforcement is classed in three categories (A, B, and $\mathrm{C}$ ), depending on their transverse stiffness and some specific geometric characteristics of the fibre strands. Textile reinforcement with a pronounced regularly repeating variation in cross-sectional dimensions along the longitudinal axis, which is also coated with a stiff impregnation material such as epoxy resin (category $\mathrm{C}$ in [21]) exhibits a high tendency for longitudinal cracking in the layer of textile reinforcement. The dominant bond mechanism in this type of reinforcement is a mechanical interlock between the reinforcement and the concrete. The numerical investigations described in this paper, as well as the introduced model, are limited to this type of textile reinforcement. The splitting forces due to bond action are calculated for a solid fibre strand, assuming that no interlaminar failure occurs in the fibre strand. This is in line with observations from experimental studies [15, 18, 22], where longitudinal cracking occurred in the concrete but the fibre strand was not damaged.

The study described in this manuscript is limited to short individual yarns. Investigations on how adjacent fibre strands interfere with each other or on how the development of the axial force in the fibre strand changes for bigger anchorage lengths are carried out elsewhere (see [22], for example).
By calculating the magnitude and distribution of the splitting forces in textile-reinforced concrete, the exposure (with respect to a bond load) $(E)$ is taken into account. Longitudinal cracking is likely to occur when the exposure exceeds the resistance $(R)$ of the concrete. The resistance $(R)$ is not investigated in detail in this manuscript but should be considered in further research, as preliminary results from various researchers indicate that both the mechanical properties of the concrete and the concrete cover influence the initiation of longitudinal cracking [16, 23, 24].

\section{Geometrical characterisation of textile reinforcement}

\subsection{Laser scanning of textile reinforcement}

To determine the geometrical properties of the textile reinforcement, optical measurements with a laser scanner were conducted. The measurement system consisted of a Nikon/Metris MCA 3600 articulated arm with a Metris MMD50 laser scanner attached. After the calibration of the portable measurement system at the installation site, the entire surface of the reinforcement was scanned. The articulated arm with the mounted laser scanner was guided by hand around the object to be scanned. By measuring the reflections of the laser, a cluster of points representing the surface of the textile reinforcement was generated. The measurement accuracy given by the manufacturer was $7 \mu \mathrm{m}$.

Algorithms were used to generate a triangulated closed surface from the cluster of points. The obtained digital 3D model is a detailed representation of the real object. This digital model was subsequently examined with the program MATLAB, making it possible not only to automatically generate the volume or surface area of the fibre strand but also to visualise cross sections of the model. In the following sections, four types of fibre strands are investigated. The types are described in a previous paper [18]. Figure 1 shows the digital models of these four types.

By comparing the different types of reinforcement, one can clearly see significant differences in configuration and strand shape. While strand type $\mathrm{R}$ has a round cross section, all the other types have a roughly flat elliptical shape. In Fig. 2 it can be seen that the 


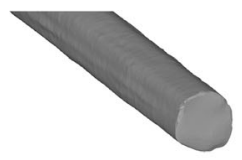

(a) Type R

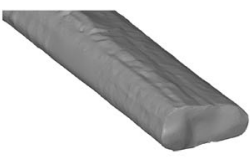

(b) Type F

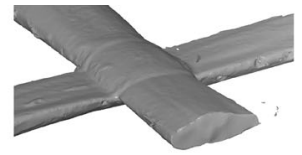

(c) Type $\mathrm{S}$

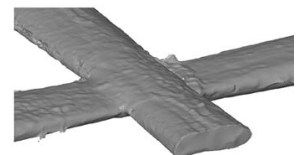

(d) Type K

Fig. 1 Diagonal view of the digital 3D models of the different types of textile reinforcement: a Round cross-sectional shape-type R; b Flat cross-sectional shape—type F; c Weft thread (German: Schussfaden)—type S; d Warp thread (German: Kettfaden)—type K

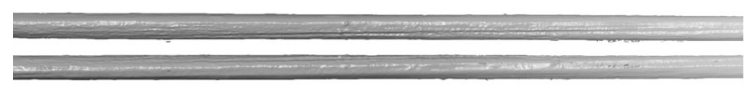

(a) Type R

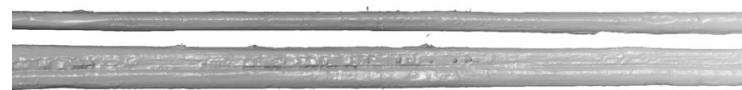

(b) Type F

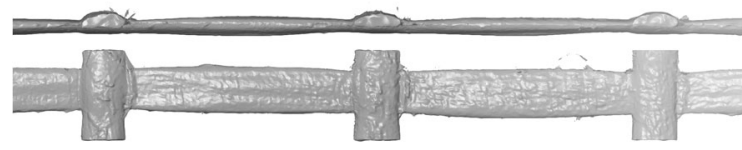

(c) Type $\mathrm{S}$

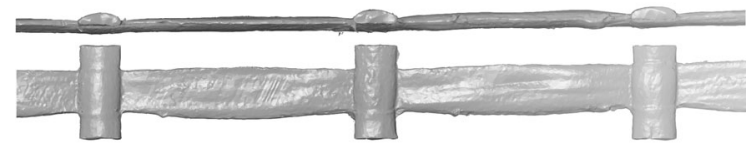

(d) Type K

Fig. 2 Side and top view of the digital 3D models of the different types of textile reinforcement

cross section of strand types $\mathrm{R}$ and $\mathrm{F}$ is constant alongside their longitudinal axis, while fibre strand types $\mathrm{S}$ and $\mathrm{K}$ exhibit local deformations at the intersections of the rovings and a widening of the strand between those intersections (a detailed longitudinal section is shown in Sect. 3.2.2). These characteristics have been identified as playing a major role in the distribution and magnitude of the splitting forces due to bond action [20]. To quantify these differences, geometrical parameters allowing the different types of fibre strands to be compared are introduced in the next section.

\subsection{Geometrical parameters}

\subsubsection{Cross-sectional shape}

To describe the cross-sectional shape of the fibre strands, parameter $k_{\mathrm{F}}$ is introduced. By dividing the circumference of the strand $U_{\mathrm{r}}$ by the circumference of a circle $U_{\mathrm{kr}}$ with the same area as the strand $A_{\mathrm{r}}$, a dimensionless form parameter is obtained which represents the compactness of the fibre strand; see Eq. (1).

$k_{\mathrm{F}}=\frac{U_{\mathrm{r}}}{U_{\mathrm{kr}}}$

and

$A_{\mathrm{r}}=A_{\mathrm{kr}}$

If parameter $k_{\mathrm{F}}$ is close to 1 , the fibre strand has an approximately round cross section. A parameter $k_{\mathrm{F}}$ greater than 1 signifies an elliptical cross section in which the ratio of the major to the minor axis increases with increasing parameter $k_{\mathrm{F}}$. Figure 3 shows the cross-section geometry of the fibre strands generated from the digital model—at the intersection of the strands and halfway between the intersections -for the four types of reinforcement. While type $\mathrm{R}$ has a nearly round cross section $\left(k_{\mathrm{F}}=1.02\right)$, type $\mathrm{K}$ exhibited a flat elliptical shape $\left(k_{\mathrm{F}}=1.30\right)$.

\subsubsection{Variation in cross-sectional area}

By visualising a horizontal section (top view) and vertical section (side view) of the fibre strand (see Fig. 4), the aforementioned regularly repeating variation in cross-sectional dimensions between the intersections with the transverse strands can be described. As the regularly spaced increase of the strand cross section is fixed by the impregnation applied during the manufacturing process, it acts like a flat rib facilitating the mechanical interlock between the fibre strand and the concrete [15]. If the fibre strand is loaded a concrete compression strut forms, originating from these ribs. Similar behaviour is observed in reinforced concrete. In textile-reinforced concrete, however, it is assumed that the flat shape of the ribs leads to the formation of a steep concrete compression strut, with the angle depending on the magnitude of the cross-sectional variation. Taking this into account, a dimensionless parameter $k_{\mathrm{A}}$ is 


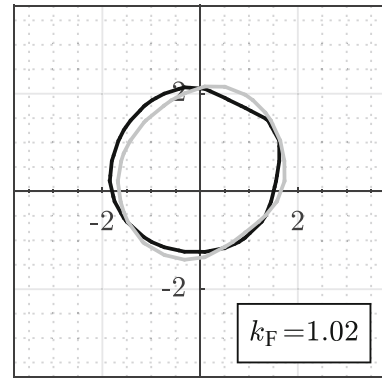

(a) Type R

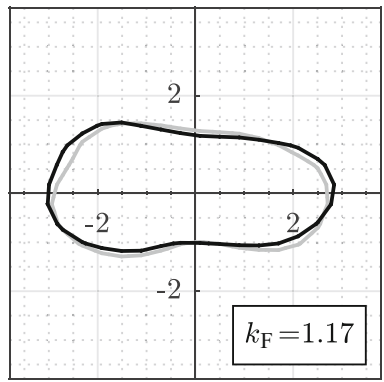

(b) Type F

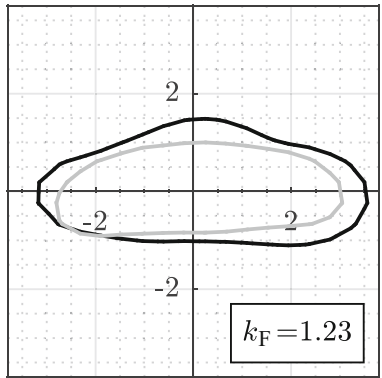

(c) Type $\mathrm{S}$

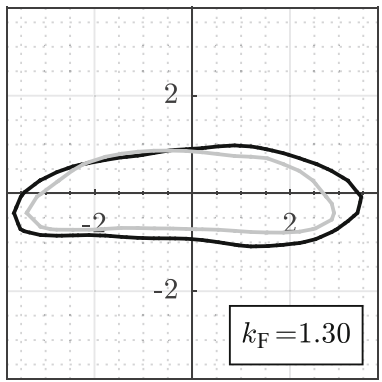

(d) Type K

Fig. 3 Representative cross sections of the fibre strands generated from the digital 3D model: at the intersection with the transverse strands (grey line) and halfway between the intersections (black line)

Fig. 4 Representative longitudinal section of fibre strand types S (left) and $\mathrm{K}$ (right): vertical section (top) and horizontal section (bottom)
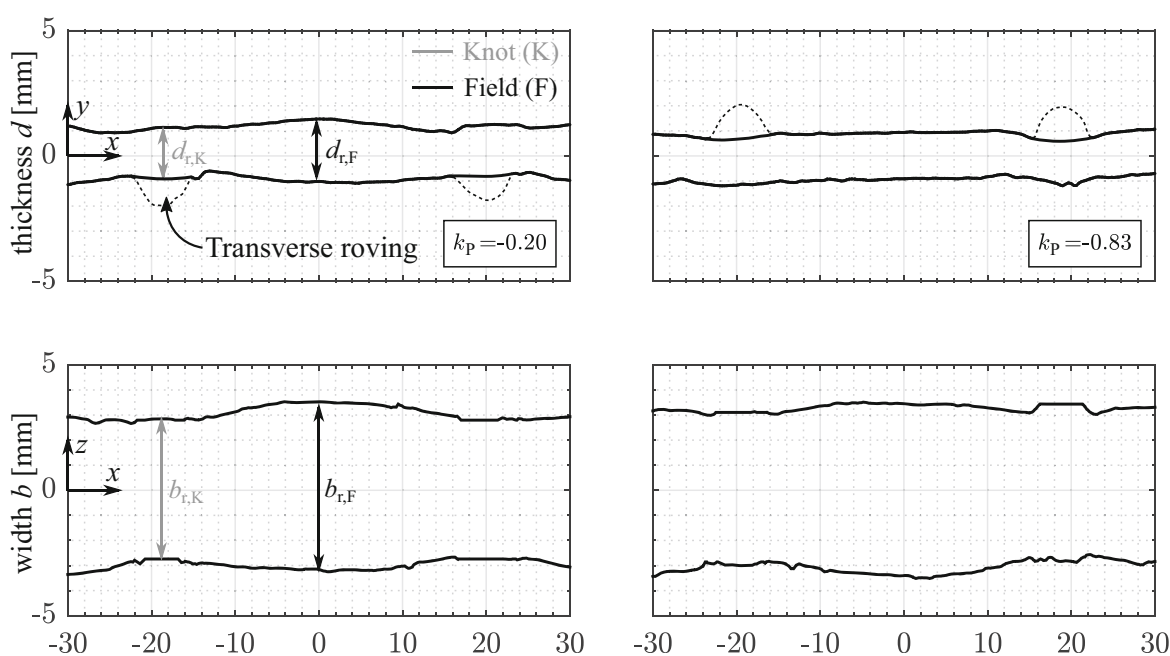

introduced which represents the ratio of the crosssectional area of the strand between the intersections with transverse fibre strands $A_{\mathrm{r}, \mathrm{F}}$ (generally a local maximum of the cross-sectional area) to the crosssectional area at the intersections $A_{\mathrm{r}, \mathrm{K}}$ (generally a local minimum of the cross-sectional area); see Eq. (2).

$k_{\mathrm{A}}=\frac{A_{\mathrm{r}, \mathrm{F}}}{A_{\mathrm{r}, \mathrm{K}}}$

\subsubsection{Dominant direction of the regularly repeating variation in cross-sectional dimensions}

Due to the production process of the textile reinforcement, the regularly repeating variation in crosssectional dimensions of the fibre strands is not uniform along their circumference. As can be seen in Fig. 4, the increase in cross-sectional dimensions is significantly greater in the direction of the width of the strand. In various sources [25], a strong influence of the variation in cross-sectional dimensions is assumed, depending on whether the increase in crosssectional dimension is greater in the direction of the width or in the direction of the thickness. To quantify this property, a third parameter $k_{\mathrm{p}}$ is introduced which relates the changes in thickness $\left(d_{\mathrm{r}, \mathrm{F}}-d_{\mathrm{r}, \mathrm{K}}\right)$ and width $\left(b_{\mathrm{r}, \mathrm{F}}-b_{\mathrm{r}, \mathrm{K}}\right)$ to the sum of the dimensional increase in both directions; see Eq. 3 .

$k_{\mathrm{P}}=\frac{\left(d_{\mathrm{r}, \mathrm{F}}-d_{\mathrm{r}, \mathrm{K}}\right)-\left(b_{\mathrm{r}, \mathrm{F}}-b_{\mathrm{r}, \mathrm{K}}\right)}{\left(d_{\mathrm{r}, \mathrm{F}}-d_{\mathrm{r}, \mathrm{K}}\right)+\left(b_{\mathrm{r}, \mathrm{F}}-b_{\mathrm{r}, \mathrm{K}}\right)}$

If parameter $k_{\mathrm{p}}$ equals 0 , there is a uniform increase in both the width and the thickness. If this parameter tends to a value of -1 , the fibre strand exhibits a 
dominant increase in the direction of the width. On the other hand, if $k_{\mathrm{p}}$ equals 1 , the dominant increase is in the direction of the thickness.

\subsubsection{Waviness}

Textile reinforcement exhibits a certain waviness, due to the production process, which is not the same as the aforementioned variation in cross-sectional dimensions of the fibre strand, but rather represents a global deflection of the longitudinal axis. This can be due either to a deflection of the strand, owing to a lack of straightening during the production process, or to an asymmetric intersection of the warp and weft threads as shown in Fig. 4, top right. To quantify this waviness, a fourth parameter $k_{\mathrm{W}}$ is introduced which relates the global deflection $f$ between two intersections to the centre-to-centre distance of the transverse strands $e$; see Eq. 4.

$k_{\mathrm{W}}=\frac{f}{e}$

If parameter $k_{\mathrm{W}}$ is 0 , the fibre strand is perfectly straight. Larger values of $k_{\mathrm{w}}$ indicate an increase in waviness, and thus an increasing global deflection of the fibre strand between the intersections with the transverse strands.

\subsection{Comparison of geometric characteristics}

In Table 1, the analysed geometrical parameters for all four types of fibre strands are listed. Since fibre strand types $\mathrm{R}$ and $\mathrm{F}$ are straight along their longitudinal axis and do not have any regularly repeating macroscopic variations in cross-section geometry, only parameter $k_{\mathrm{F}}$ is of importance for these strand types. In contrast, fibre strand types $\mathrm{S}$ and $\mathrm{K}$ both exhibit a pronounced regularly repeating variation in cross-section geometry. This variation is expressed by parameter $k_{\mathrm{A}}$.

Strand types $\mathrm{S}$ and $\mathrm{K}$ differ by their production process. If the strand is wrapped with knitting yarn (as is the case for the warp thread-type K), a more compact shape of the fibre strand is obtained, resulting not only in a smaller parameter $k_{\mathrm{A}}$ but also in a smaller regularly repeating dimensional variation in the thickness direction of the strand. Nonetheless, due to the compression of the fibre strand during the impregnation process, which serves to facilitate the full impregnation of the roving, both fibre strands also exhibit an increase in the direction of the width between the intersections with the transverse fibre strands. These geometric characteristics are represented by parameter $k_{\mathrm{p}}$, as fibre strand type K shows a dominant increase in the width direction, while fibre strand type $\mathrm{S}$ exhibits a roughly uniform widening of the strand along its circumference. Lastly, it should be mentioned that all strand types are largely straight longitudinally, with only types $\mathrm{K}$ and $\mathrm{S}$ showing minimal deflections. Therefore, the waviness of the fibre strands can be neglected.

\section{Parametric study}

In experimental and numerical calculations carried out in [20], it was shown that the geometry of the fibre strand is the main influencing parameter for the magnitude and distribution of the splitting forces due to bond action. In this section, a parametric study is presented, in which the geometrical parameters introduced in Sect. 3.2 are varied in a predefined range in order to quantify the impact of each

Table 1 Geometric characteristics of the four types of fibre strands (mean values for a $400 \mathrm{~mm}$ fibre strand)

\begin{tabular}{|c|c|c|c|c|c|c|c|c|c|c|c|c|c|c|}
\hline Type & $\begin{array}{l}d_{\mathrm{r}, \mathrm{F}} \\
(\mathrm{mm})\end{array}$ & $\begin{array}{l}b_{\mathrm{r}, \mathrm{F}} \\
(\mathrm{mm})\end{array}$ & $\begin{array}{l}d_{\mathrm{r}, \mathrm{K}} \\
(\mathrm{mm})\end{array}$ & $\begin{array}{l}b_{\mathrm{r}, \mathrm{K}} \\
(\mathrm{mm})\end{array}$ & $\begin{array}{l}A_{\mathrm{r}, \mathrm{F}} \\
\left(\mathrm{mm}_{2}\right)\end{array}$ & $\begin{array}{l}A_{\mathrm{r}, \mathrm{K}} \\
\left(\mathrm{mm}_{2}\right)\end{array}$ & $\begin{array}{l}U_{\mathrm{r}, \mathrm{F}} \\
(\mathrm{mm})\end{array}$ & $\begin{array}{l}U_{\mathrm{r}, \mathrm{K}} \\
(\mathrm{mm})\end{array}$ & $\begin{array}{l}e \\
(\mathrm{~mm})\end{array}$ & $\begin{array}{l}f \\
(\mathrm{~mm})\end{array}$ & $\begin{array}{l}k_{\mathrm{F}} \\
(-)\end{array}$ & $\begin{array}{l}k_{\mathrm{A}} \\
(-)\end{array}$ & $k_{\mathrm{P}}(-)$ & $\begin{array}{l}k_{\mathrm{W}} \\
(-)\end{array}$ \\
\hline $\mathrm{R}$ & $3.48^{\mathrm{a}}$ & $3.37^{\mathrm{a}}$ & - & - & $9.29^{\mathrm{a}}$ & - & $11.00^{\mathrm{a}}$ & - & - & - & 1.018 & 1.000 & 0.000 & 0.000 \\
\hline F & $2.69^{\mathrm{a}}$ & $5.91^{\mathrm{a}}$ & - & - & $11.75^{\mathrm{a}}$ & - & $14.21^{\mathrm{a}}$ & - & - & - & 1.170 & 1.000 & 0.000 & 0.000 \\
\hline$S$ & 2.49 & 6.69 & 1.76 & 5.56 & 13.25 & 8.85 & 15.61 & 13.16 & 38.00 & 0.40 & 1.234 & 1.500 & -0.200 & 0.010 \\
\hline K & 1.84 & 6.85 & 1.77 & 5.91 & 11.33 & 8.15 & 15.51 & 13.23 & 38.00 & 0.08 & 1.302 & 1.390 & -0.834 & 0.002 \\
\hline
\end{tabular}

${ }^{a}$ In fibre strand types $\mathrm{R}$ and $\mathrm{K}$ no intersecting transverse fibre strand was present. For these strand types, index r,F represents the mean value along the whole length of the fibre strand 
parameter on the development of the splitting forces. A total of 75 calculations were carried out. The dimensions of all the fibre strands used in the parametric study are listed in [23].

1 Cross-section geometry: Variation of parameter $k_{\mathrm{F}}$ within the limit 1.0:0.1:1.4 (start value:step: end value)

2 Dominant direction of the regularly repeating variation in the cross-sectional dimensions: Variation of parameter $k_{\mathrm{P}}$ within the limit -1.0:0.5:1.0

3 Magnitude of the regularly repeating variation in cross-sectional area: Variation of parameter $k_{\mathrm{A}}$ within the limit 1.2:0.3:1.8

The influence of the waviness of the fiber strand has been extensively investigated by Lorenz et.al; e.g. [26]. The optical measurements of the different investigated fiber strands in this manuscript (Sect. 3.3) showed that all used samples of textile reinforcement were almost straight in longitudinal direction, therefore allowing for a disregard of the influence of the waviness in the following sections. For higher values of the waviness the authors are referring to the calculation of the deviation forces by Lorenz et.al. [26].

\subsection{Numerical model}

The parametric study was conducted within the program Abaqus/CAE by Dassault systems. This study used a numerical model of a pull-out test, which was defined by the authors and presented in a previous publication [20] (see Fig. 5). The modelling framework is based on a single-sided pull-out test (SPO) that is typically used to determine the bond behaviour of textile-reinforced concrete [16, 27, 28]. Only the upper part of the test setup is modelled, whereas the bottom part is taken into account by using appropriate boundary conditions.

The model parameters, which had previously been determined by the authors [20], are summarised in Table 2. For compression and tension, the nonlinearity of the concrete is considered by implementing the model according to EN 1992-1-1 [29] and by using the fictitious crack model developed by Hillerborg [30], respectively. The concrete damage plasticity model (CDP) described in [31] was chosen as the damage hypothesis in order to simulate the damage progression in the concrete. The fibre strand is

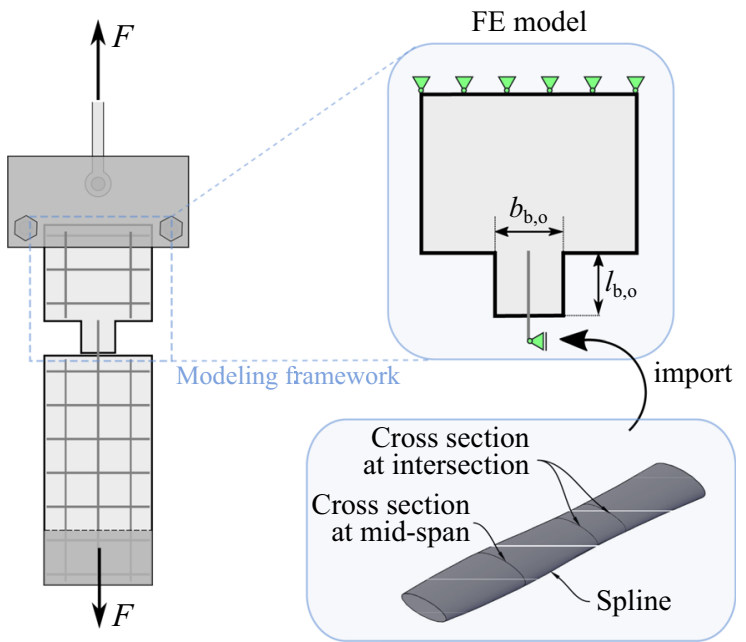

Fig. 5 Numerical model of a pull-out test on textile-reinforced concrete defined by [20]: Real test setup for a pull-out test according to [15] (left), numerical model with boundary conditions (top right), and approximation of the fibre strand, which is then imported into the FE model (bottom right)

implemented to exhibit transverse isotropic material behaviour, which means that there are only five independent input parameters. The input parameters were chosen according to calculations carried out in $[32,33]$. To model the interface, hard contact between the solid, homogenous fibre strand and the concrete was implemented to simulate mechanical interlock, and an interaction between the concrete and fibre strand in the interface which takes into account both adhesion (linear contact stiffness with exponential damage progression after a predefined displacement has been reached) and friction (based on Coulomb's friction hypothesis) was modelled. The material parameters of the interface were initially estimated according to calculations presented in [34] and subsequently determined more accurately by the authors within a calibration process.

\subsection{Python script and output values}

For the parametric study, the fibre strand is parameterised at a local minimum (e.g. at the position where a transverse fibre strand would cross) and a local maximum (e.g. halfway between local minima where transverse fibre strands would cross) by defining the ellipse parameters $a_{\mathrm{K}}$ and $b_{\mathrm{K}}$, and $a_{\mathrm{F}}$ and $b_{\mathrm{F}}$, respectively (where $a>b$ ); see Fig. 6. The different types of fibre strands were generated in 
Table 2 Model parameters chosen according to [20]

Concrete (model according to EC2)

\begin{tabular}{lllll}
\hline$f_{\mathrm{cm}}\left(\mathrm{N} / \mathrm{mm}^{2}\right)$ & $\mathrm{\square}_{\mathrm{c} 1}(-)$ & $\mathrm{\square}_{\mathrm{cu}}(-)$ & $f_{\mathrm{ctm}}\left(\mathrm{N} / \mathrm{mm}^{2}\right)$ & $G_{\mathrm{f}}(\mathrm{N} / \mathrm{mm})$ \\
\hline 78.0 & 2.8 & 2.8 & 4.82 & 60.0
\end{tabular}

Damage hypothesis (concrete damage plasticity model)

\begin{tabular}{llll}
\hline$\square\left({ }^{\circ}\right)$ & $\square(-)$ & $\square_{\mathrm{b} 0} / \mathrm{Q}_{\mathrm{c} 0}(-)$ & $K_{\mathrm{c}}(-)$ \\
\hline 35 & 0.1 & 1.16 & 0.67 \\
\hline
\end{tabular}

Textile reinforcement

\begin{tabular}{lllll}
\hline$E_{\|}\left(\mathrm{kN} / \mathrm{mm}^{2}\right)$ & $E \perp\left(\mathrm{kN} / \mathrm{mm}^{2}\right)$ & ll $(-)$ & $\square \perp(-)$ & $G_{\|}\left(\mathrm{kN} / \mathrm{mm}^{2}\right)$ \\
\hline 205 & 13.79 & 0.2 & 0.25 & 8.97 \\
\hline
\end{tabular}

Interface

\begin{tabular}{lllll}
\hline$K_{\mathrm{TT}}\left(\mathrm{N} / \mathrm{mm}^{3}\right)$ & $\delta_{\mathrm{m}}^{\mathrm{o}}(\mathrm{mm})$ & $\delta_{\mathrm{m}}^{\mathrm{f}}(\mathrm{mm})$ & $\square(-)$ & $\square(-)$ \\
\hline 1000 & 0.004 & 0.4 & 0.05 & 0.5 \\
\hline
\end{tabular}

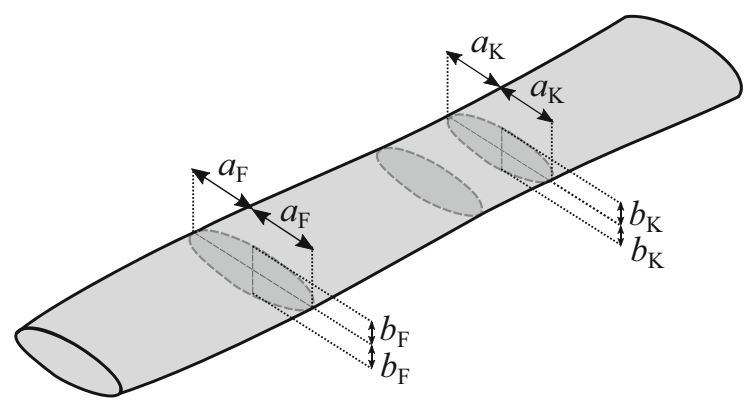

Fig. 6 Parameterisation of the fibre strand: $a_{\mathrm{k}}$ and $b_{\mathrm{k}}$ are the ellipse parameters at the local minimum, and $a_{\mathrm{F}}$ and $b_{\mathrm{F}}$ are the ellipse parameters at the local maximum

AutoCAD as volumetric models by defining these distinctive cross sections. Between the distinct cross sections the fibre strand was approximated by using a spline.

The target values for $k_{\mathrm{F}}, k_{\mathrm{P}}$, and $k_{\mathrm{A}}$ were set as fixed values, so that parameters $a_{\mathrm{K}}, a_{\mathrm{F}}, b_{\mathrm{K}}$, and $b_{\mathrm{F}}$ had to be varied within a target value iteration until the desired parameter values were obtained. The modelling of the fibre strand itself was carried out automatically with a Visual Basic script within the AutoCAD environment. Thereafter, a Python script was created to automatically generate the desired numerical model, including the import of the fibre strand, execution of the calculations, and generation of the desired output values for all 75 test specimens.
Besides the pull-out load $F_{\mathrm{x}}$ and the slip $u_{\mathrm{x}, \mathrm{A}}$ of the fibre strand, the splitting forces in the test specimens are of major interest for the interpretation of the results. These forces are calculated by integrating the stresses in the $y$-direction (perpendicular to the layer of textile reinforcement) and the $z$-direction (in the plane of the layer of textile reinforcement; see Fig. 7).

\subsection{Results}

The results of the numerical calculation were visualised in $3 \mathrm{D}$ plots, where parameters $k_{\mathrm{F}}$ and $k_{\mathrm{P}}$ are shown on the horizontal axes, and the ratio of the splitting forces $F_{\mathrm{sp}, \mathrm{y}} / F_{\mathrm{sp}, \mathrm{z}}$ is plotted on the vertical axis. Parameter $F_{\mathrm{sp}, \mathrm{y}}$ describes the splitting force directed orthogonally to the layer of textile

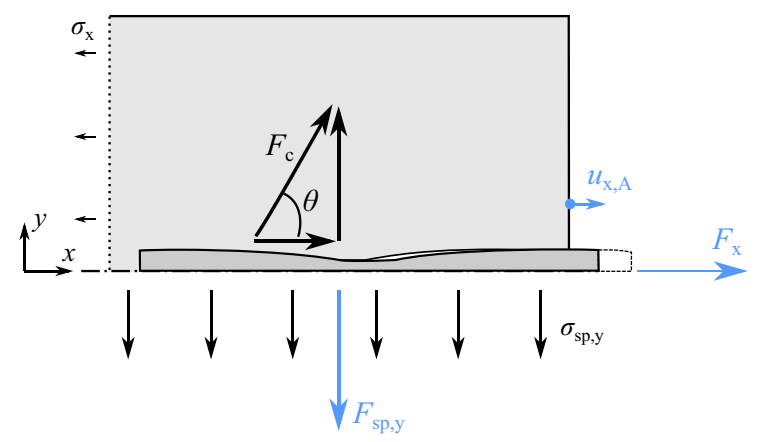

Fig. 7 Output values of the numerical calculations (in blue) 
reinforcement which leads to the spalling of the concrete cover, whereas $F_{\mathrm{sp}, \mathrm{z}}$ is the splitting force in the plane of the layer of textile reinforcement. 3D plots were generated for three values of the parameter for the regularly repeating variation in cross-sectional dimensions $k_{\mathrm{A}}$ (see Fig. 8). For the evaluation of the splitting force ratio $F_{\mathrm{sp}, \mathrm{y}} / F_{\mathrm{sp}, \mathrm{z}}$, a load stage was chosen at which the concrete section was still uncracked (75\% of the ultimate load). This was done to ensure that no significant redistribution of the concrete stresses had occurred and that the FE model can be assumed to represent a homogenous continuum.

In the plots in Fig. 8 it can be seen that there is no significant difference between the ratios of the splitting forces $F_{\mathrm{sp}, \mathrm{y}} / F_{\mathrm{sp}, \mathrm{z}}$ for different magnitudes of the regularly repeating variation in cross-sectional dimensions, described by parameter $k_{\mathrm{A}}$. On the other hand, parameters $k_{\mathrm{F}}$ and $k_{\mathrm{P}}$ were both observed to have a significant influence on the splitting forces. To paint a clear picture of the influence of these two parameters, 2D graphs were extracted from the 3D plots. Additionally, the ratio $F_{\mathrm{sp}, \mathrm{y}} / F_{\mathrm{sp}, \mathrm{z}}$ was dissolved, and the splitting forces are displayed individually on the $y$-axis as a function of the axial force $F_{\mathrm{x}}$ in the fibre strand.

Figure 9 (left) shows a clear dependency of the distribution of the splitting forces on parameter $k_{\mathrm{F}}$. While the splitting forces in a circular cross section are obviously of the same magnitude in both the $y$ and $z$-direction (any small differences observed are due to numerical inaccuracies), the splitting forces in the $y$-direction $F_{\mathrm{sp}, \mathrm{y}}$ become increasingly more dominant with increasing flatness of the fibre strand (represented by parameter $k_{\mathrm{F}}$ ). These results agreed with those of experimental investigations previously carried out by the authors [18] in which the experimental data showed a strong dependency of the cracking pattern on the fibre strand cross-section geometry

Figure 9 (right) also shows a clear dependency of the dominant direction of the regularly repeating variation in cross-sectional dimensions on the splitting forces, displayed in terms of parameter $k_{\mathrm{p}}$. If the cross-sectional variation is due predominantly to a widening of the fibre strand, the splitting forces in the $z$-direction are larger than those in the $y$-direction. If, however, the cross-sectional variation is due mainly to a thickening of the fibre strand, the opposite $\left(F_{\mathrm{sp}}\right.$, y $\left.>F_{\text {sp }, \mathrm{z}}\right)$ can be observed.

\subsection{Classification of own experimental data}

To conclude this section, fibre strand types $\mathrm{S}$ and $\mathrm{K}$, the geometric characteristics of which are described in Sect. 3.3, are classified according to the results of the parametric study by referring to Fig. 9. In the first step, the value of the governing parameter (either $k_{\mathrm{F}}$ if the diagram in Fig. 9 left is used or $k_{\mathrm{P}}$ if the diagram in Fig. 9 right is used) is marked on the $x$ axis (the horizontal axis). A vertical line is drawn from this value to the intersection with the governing curve of parameter $k_{\mathrm{P}}$ or $k_{\mathrm{F}}$, respectively. From this intersection, a horizontal line is drawn to intersect the vertical $y$-axis. The value at the intersection represents the ratio of the splitting force $F_{\text {sp.y }}$ to the tensile force in the fibre strand $F_{\mathrm{x}}$. It can be seen that fibre strand type $S$ induces slightly higher splitting forces
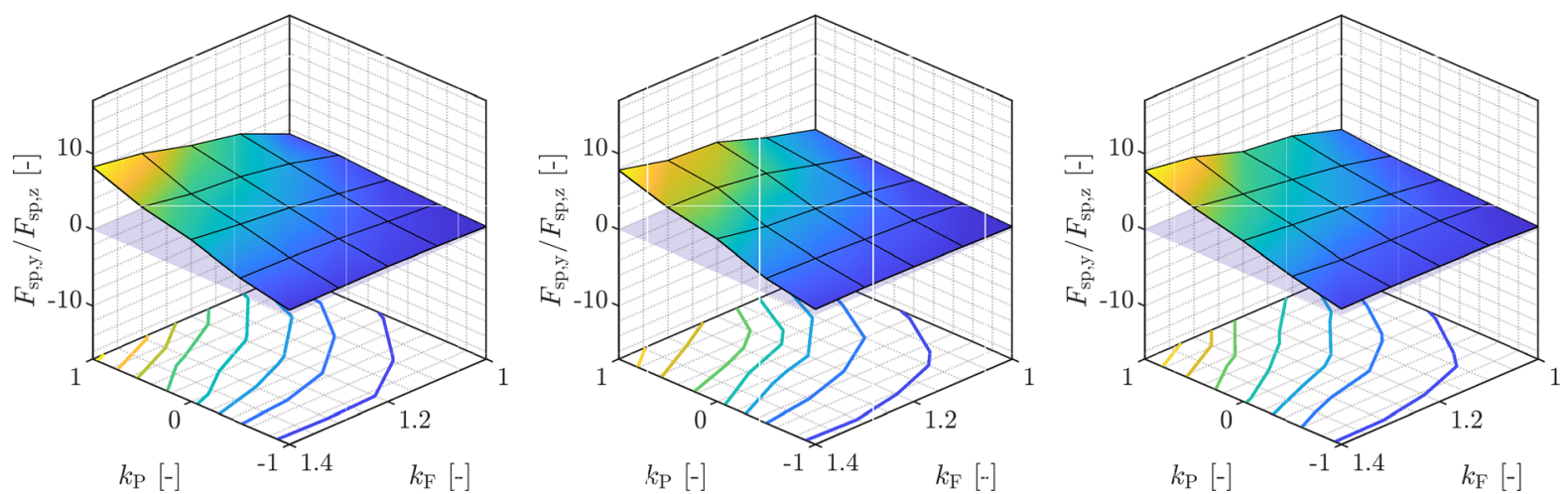

Fig. 8 Splitting force ratio $F_{\mathrm{sp}, \mathrm{y}} / F_{\mathrm{sp}, \mathrm{z}}$ vs. parameters $k_{\mathrm{F}}$ and $k_{\mathrm{P}}$ for three values of the cross-sectional parameter $k_{\mathrm{A}}: k_{\mathrm{A}}=1.2\left(\right.$ left); $k_{\mathrm{A}}=$ 1.5 (centre); $k_{\mathrm{A}}=1.8$ (right) 
Fig. 9 Ratios of the splitting forces to the axial force in the fibre strand $F_{\mathrm{sp}, \mathrm{y}} / F_{\mathrm{x}}$ and $F_{\mathrm{sp}, \mathrm{z}} / F_{\mathrm{x}}$ for cross-sectional parameter $k_{\mathrm{A}}=1.5$ vs. parameters $k_{\mathrm{F}}$ (left) and $k_{\mathrm{P}}$ (right). Only fibre strand types $\mathrm{S}$ and $\mathrm{K}$ were analysed

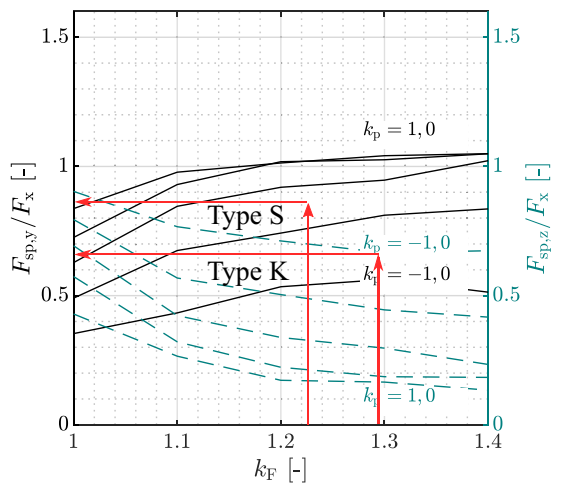

in the concrete than fibre strand type $\mathrm{K}$. This is consistent with the experimental data reported in [22], where all specimens reinforced with fibre strand type $S$ failed earlier than specimens reinforced with fibre strand type K. Nonetheless, it should be noted that there is scatter in the results, which is mainly due to inaccuracies in the manufacturing process of the fibre strands. In pull-out tests on both types of fibre strands reported in [18] the two types failed at nearly the same load stage, and hence the spread of the maximum peak load values was not as great as that of the numerical results reported in this paper. However, the parametric study clearly shows how different geometrical parameters influence the magnitude and distribution of the splitting forces due to bond action in textile-reinforced concrete.

\section{Splitting force model (SF-model)}

In this section, a mechanical model is introduced which permits the calculation of the splitting forces that occur when a single short fibre strand is pulled out of the concrete, as a function of the geometric characteristic of the fibre strand. Mechanical interlock between the fibre strand and the concrete is required to ensure the validity of the model, which is achieved by using textiles of category $\mathrm{C}$ (as defined in [21]). Like in the model for steel-reinforced concrete presented in [35], in which inclined concrete compressive stresses originate from the steel reinforcement ribs, concrete compression struts also occur in textile-reinforced concrete when the fibre strand is loaded. The regularly spaced increase in cross-sectional dimensions acts as a flat rib in textilereinforced concrete, as shown in [18]. The concrete compressive stresses are in equilibrium with the tensile hoop stresses. Two geometrical parameters $\left(k_{\mathrm{F}}\right.$ and $k_{\mathrm{p}}$ ) have been shown to play a major role in the distribution of the concrete compressive stresses along the circumference of the fibre strand in textile-reinforced concrete and on the tensile hoop stresses which can cause splitting failure if they exceed the concrete tensile strength.

\subsection{Concrete compression strut}

The magnitude of the splitting forces strongly depends on the inclination $\square$ of the concrete compression strut $\mathrm{Fc}$ with respect to the layer of textile reinforcement (see Fig. 7). This can be expressed by simple trigonometry:

$F_{\mathrm{sp}}=\tan \theta \cdot F_{\mathrm{c}}$

By considering both the experimental and numerical calculations published in [20] and the parametric study carried out in this research, it was determined that the inclination of the strut is very steep. It is assumed that the magnitude of the regularly repeating variation in cross-sectional dimensions of the fibre strand (represented by parameter $k_{\mathrm{A}}$ ) can have an influence on the strut inclination. If the crosssectional dimensions of the fibre strand increase only a little, mechanical interlock is achieved by a wedge effect, resulting in steep concrete compression struts. If the increase in cross-sectional dimension is pronounced, the concrete compression strut forms due to a steep rib being pressed against the concrete. However, within the range of the varied parameter $k_{\mathrm{A}}$ (between 1.2 and 1.8), no significant change in the inclination of the concrete compression strut was observed $\left(60^{\circ} \pm 1^{\circ}\right)$. The values were calibrated 
according to Sect. 5.4. Due to the small difference in concrete compression strut inclination for all investigated values of parameter $k_{\mathrm{A}}$, the inclination is set to a constant value of $60^{\circ}$.

\subsection{Influence of the cross-section geometry of the fibre strand}

If a fibre strand exhibits a flat elliptical cross-section geometry, the resulting splitting forces are assumed to be higher in the direction of the minor axis, while a circular fibre strand induces uniform splitting stresses along its circumference (see Fig. 10; top). To determine the magnitude of the resulting splitting forces $F_{\mathrm{sp}}$, y and $F_{\mathrm{sp}, \mathrm{z}}$ in the $y$ - and $z$-directions, the distribution of the concrete tensile stresses is simplified according to Fig. 10; bottom. In the following approach, the ratio of the two ellipse axes is of interest, and this will be visualised as a function of the parameter describing the fibre strand cross-section geometry, $k_{\mathrm{F}}$.

The circumference of the fibre strand $U_{\mathrm{r}}$ is approximated by Eq. (6), as no perfect solution for the calculation of the circumference of an ellipse exists.
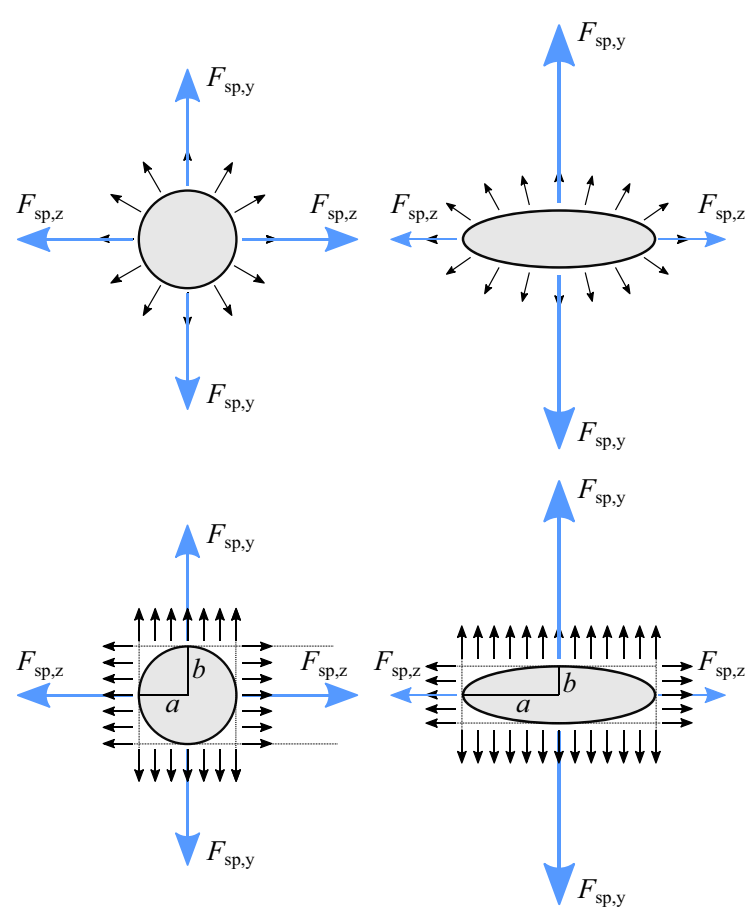

Fig. 10 Splitting forces for two different fibre strand crosssection geometries: Real magnitude and distribution (top) and simplified distribution of concrete tensile stresses (bottom)
$U_{\mathrm{r}} \sim \pi \cdot\left(3 \cdot \frac{a+b}{2}-\sqrt{a b}\right)$

By equating the area of an ellipse with that of a circle

$a \cdot b \cdot \pi=r^{2} \cdot \pi$

the radius of the equivalent circle is obtained:

$r=\sqrt{a \cdot b}$

The circumference of a circle $U_{\mathrm{kr}}$ can be expressed by

$U_{\mathrm{kr}}=2 \cdot r \cdot \pi=2 \cdot \sqrt{a \cdot b} \cdot \pi$

Substituting Eqs. (1) and (6) into Eq. (9) yields the following relation:

$k_{\mathrm{F}} \cdot 2 \cdot \sqrt{a \cdot b} \cdot \pi=\pi \cdot\left(3 \cdot \frac{a+b}{2}-\sqrt{a b}\right)$

$\sqrt{a \cdot b} \cdot\left(2 \cdot k_{\mathrm{F}}+1\right)=3 \cdot \frac{a+b}{2}$

By substituting

$\lambda=2 \cdot k_{\mathrm{F}}+1$

into Eq. (11), the following equation is obtained:

$a^{2}-2 \cdot a \cdot b \cdot\left(\frac{2}{9} \cdot \lambda^{2}-1\right)+b^{2}=0$

One solution of this quadratic equation is:

$a=b \cdot\left(\frac{2}{9} \cdot \lambda^{2}+\frac{2}{3} \cdot \lambda \sqrt{\frac{1}{9} \cdot \lambda^{2}-1}-1\right)$

Equation (14) allows the ellipse axes to be expressed as a function of parameter $k_{\mathrm{F}}$ (see Fig. 11). The plotted values in Fig. 11 correspond well with the curve obtained from the parametric study presented in Sect. 4.3 (see the curve in Fig. 9 for $k_{\mathrm{P}}=0$ ).

To take into account the fibre strand cross-section geometry, parameter $\square_{F}$ is introduced, which allows for the scaling of the resulting splitting forces according to the magnitude of parameter $k_{\mathrm{F}}$.

$$
\begin{aligned}
& \alpha_{\mathrm{F}}=\frac{a}{(a+b)} \\
& F_{\mathrm{sp}, \mathrm{y}}=\alpha_{\mathrm{F}} \cdot F_{\mathrm{sp}} \\
& F_{\mathrm{sp}, \mathrm{z}}=\left(1-\alpha_{\mathrm{F}}\right) \cdot F_{\mathrm{sp}}
\end{aligned}
$$




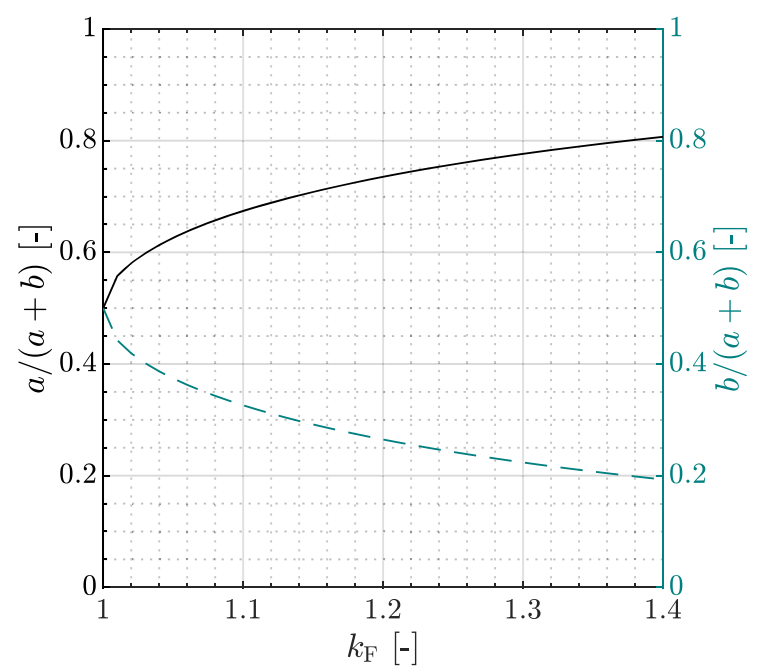

Fig. 11 Ratio of the length of an individual ellipse axis to the sum of the length of both ellipse axes, expressed as a function of parameter $\mathrm{k}_{\mathrm{F}}$

\subsection{Influence of the dominant direction} of the regularly repeating variation in crosssectional dimensions

A decisive influence of the dominant direction of the regularly repeating variation in cross-sectional dimensions, which is represented by parameter $k_{\mathrm{P}}$, was observed in the parametric study. The splitting forces are greater in the direction of the greatest variation in the cross-sectional dimension, for example in the $z$-direction if there is a pronounced widening of the fibre strand, or in the $y$-direction if there is a pronounced thickening of the strand (see Fig. 12).

To determine the distribution of the splitting forces as a function of the dominant direction of the regularly repeating cross-sectional variation described by parameter $k_{\mathrm{P}}$, a segment of the fibre strand between $\pi / 2$ and $\pi$ is displayed in Fig. 13. Compared to a circular cross section (displayed in light grey), the fibre strand exhibits a widening of the cross section. In the following calculations, it is assumed that the resulting splitting force is in direction of the centre of gravity of the widened part of the cross section (displayed in dark grey). The inclination $\square$ of the resulting splitting force with respect to the horizontal $x z$-plane of the fibre strand reflects the ratio of the magnitudes of the splitting forces $F_{\mathrm{sp}, \mathrm{y}} / F_{\mathrm{sp}, \mathrm{z}}$.

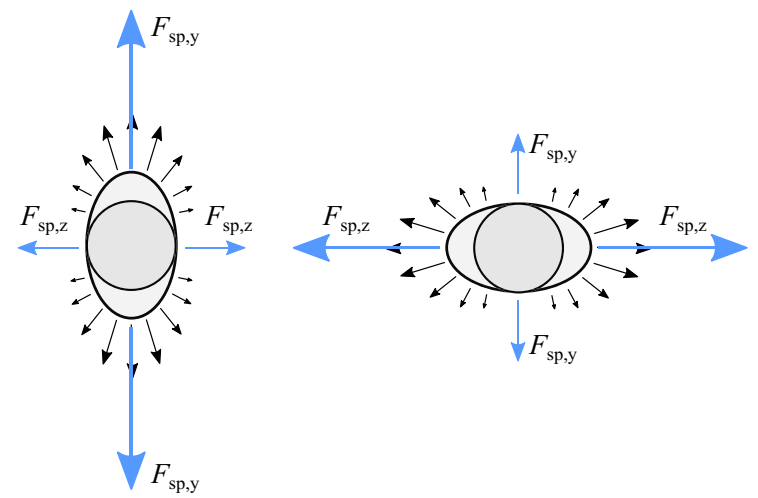

Fig. 12 Distribution of the splitting stresses as a function of the dominant direction of the regularly repeating variation in cross-sectional dimensions

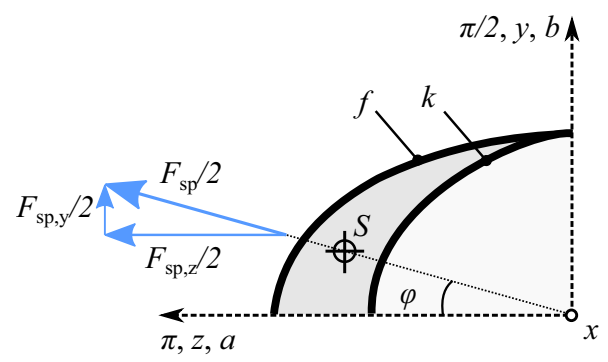

Fig. 13 Inclination of the splitting forces with respect to the $x z$-plane for a dominant widening of the cross section

The centre of gravity of the area between curves $f_{(z)}$ and $k_{(z)}$ shown in Fig. 13 is calculated by:

$S_{\mathrm{Z}}=\frac{\int_{a_{\mathrm{K}}}^{a_{\mathrm{F}}} z \cdot[f(z)-k(z)] \mathrm{d} x}{\int_{a_{\mathrm{K}}}^{a_{\mathrm{F}}}[f(z)-k(z)] \mathrm{d} x}$

$S_{\mathrm{y}}=\frac{\int_{a_{\mathrm{K}}}^{a_{\mathrm{F}}} y \cdot[f(z)-k(z)] \mathrm{d} x}{\int_{a_{\mathrm{K}}}^{a_{\mathrm{F}}}[f(z)-k(z)] \mathrm{d} x}$

Transformation into polar coordinates:

$z=r \cdot a \cdot \cos \varphi$

$y=r \cdot b \cdot \sin \varphi$

An area element of infinitesimal size is used:

$\mathrm{d} A=r \cdot a \cdot b \cdot \mathrm{d} r \cdot \mathrm{d} \varphi$

The coordinates of the centre of gravity are obtained by solving the integrals of Eqs. (18) and (19) between the limits $\pi / 2$ and $\pi$ : 
$z_{\mathrm{s}}=\frac{4 \cdot\left(a_{\mathrm{F}} \cdot b_{\mathrm{F}}^{2}-a_{\mathrm{K}} \cdot b_{\mathrm{K}}^{2}\right)}{3 \cdot \pi \cdot\left(a_{\mathrm{F}} \cdot b_{\mathrm{F}}-a_{\mathrm{K}} \cdot b_{\mathrm{K}}\right)}$

$y_{\mathrm{s}}=\frac{4 \cdot\left(a_{\mathrm{F}}^{2} \cdot b_{F}-a_{\mathrm{K}}^{2} \cdot b_{\mathrm{K}}\right)}{3 \cdot \pi \cdot\left(a_{\mathrm{F}} \cdot b_{\mathrm{F}}-a_{\mathrm{K}} \cdot b_{\mathrm{K}}\right)}$

The inclination of the concrete compression strut with respect to the $x z$-plane is thus calculated to be:

$\varphi=\cot \frac{a_{\mathrm{F}}^{2} \cdot b_{\mathrm{F}}-a_{\mathrm{K}}^{2} \cdot b_{\mathrm{K}}}{a_{\mathrm{F}} \cdot b_{\mathrm{F}}^{2}-a_{\mathrm{K}} \cdot b_{\mathrm{K}}^{2}}$

The resulting splitting forces can then be calculated according to Fig. 13:

$F_{\mathrm{sp}, \mathrm{y}}=F_{\mathrm{sp}} \cdot \sin \varphi$

$F_{\mathrm{sp}, \mathrm{z}}=F_{\mathrm{sp}} \cdot \cos \varphi$

The evaluation of the splitting forces as a function of the dominant direction of the regularly repeating cross-sectional variation was carried out for a fibre strand with a circular cross section at the intersections with the transverse strand and a pronounced regularly repeating widening of the cross section between the intersections (see Fig. 14). A clear similarity between this curve and the results from the numerical study can be seen (see, for example, the curve in Fig. 9 right for $k_{\mathrm{F}}=1.0$ ). This indicates that the assumption of the splitting force being directed to the centre of gravity of the widened portion of the cross section yields sufficiently accurate results.

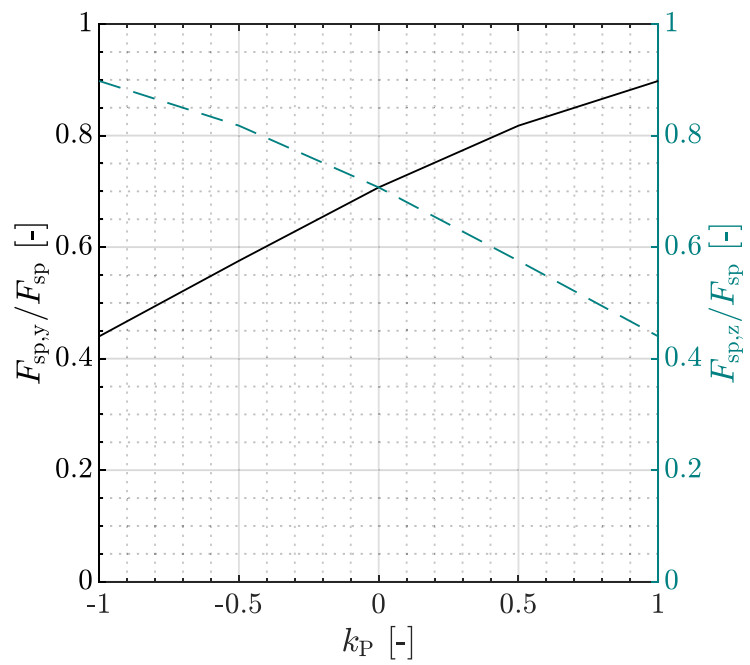

Fig. 14 Ratio of the splitting forces as a function of parameter $k_{\mathrm{P}}$

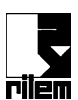

\subsection{Modelling approach}

Considering the findings from Sects. 5.1-5.3, the splitting forces due to bond action that occur when a single short strand is pulled out of the concrete can be calculated by:

$F_{\text {sp,y }}=\alpha_{\mathrm{F}} \cdot \sin \varphi \cdot \tan \theta \cdot F_{\mathrm{x}}$

$F_{\mathrm{sp}, \mathrm{z}}=\left(1-\alpha_{\mathrm{F}}\right) \cdot \cos \varphi \cdot \tan \theta \cdot F_{\mathrm{x}}$

where $\mathrm{Q}_{\mathrm{F}}$ is the parameter capturing the effect of the cross-sectional geometry on the distribution of the splitting forces (see Sect. 5.2; Eq. 15); $\square$ is describing the inclination of the splitting forces with respect to the $x z$-plane due to the presence of a dominant direction of regularly repeating variation in the crosssectional dimensions (see Sect. 5.3; Eq. 25); 0 is the inclination of the concrete compression strut with respect to the longitudinal axis of the fibre strand due to a regularly repeating variation in cross-sectional dimensions (see Sect. 5.1; Eq. 5).

In this paragraph, Eq. (28) is evaluated for parameters $k_{\mathrm{F}}$ and $k_{\mathrm{P}}$ within the range defined in the numerical study described in Sect. 4.2. Parameter $k_{\mathrm{A}}$ is set to be 1.50. In Fig. 15 the results from Eq. (28; $\left.F_{\text {sp,y,cal }}\right)$ are plotted on the $x$-axis, while the results obtained from the parametric study presented in Sect. $4.2\left(F_{\text {sp,y,num }}\right)$ are plotted on the $y$-axis. It can be seen that the results agree well with each other. The increasing divergence of the results at higher splitting forces can be attributed to the decrease in accuracy of Eq. (6) with increasing parameter $k_{\mathrm{F}}$.

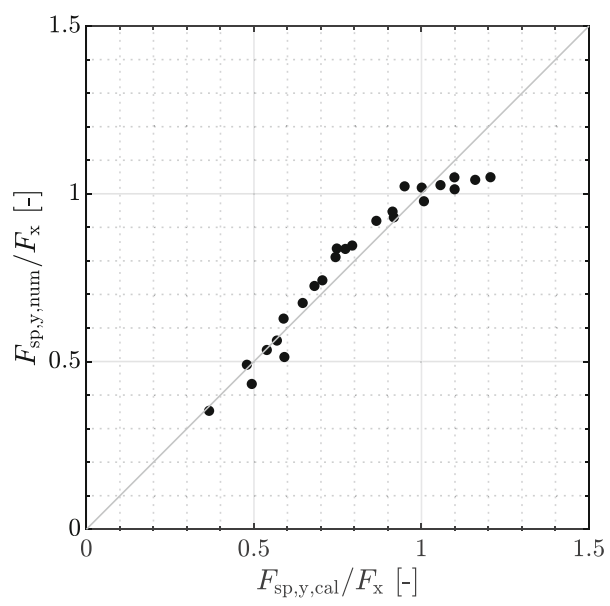

Fig. 15 Comparison of the results of the parametric study and of the calculation according to Eq. (28) 


\section{Conclusion}

Textile reinforcement is characterised by a wide variation in its geometric and mechanical characteristics. In various publications, it has been shown that the geometric characteristics play a major role in the propagation of longitudinal cracks in the layer of textile reinforcement which can lead to a spalling of the concrete cover. The authors have carried out broad experimental and numerical studies on this topic, from which the following conclusions are drawn:

- By introducing four geometrical parameters, a geometrical characterisation of different types of fibre strands can now be performed. These parameters represent the description of the cross-section geometry $\left(k_{\mathrm{F}}\right)$, the magnitude of the regularly repeating variation in cross-sectional dimensions $\left(k_{\mathrm{A}}\right)$, the dominant direction of this regularly repeating variation $\left(k_{\mathrm{P}}\right)$, and the waviness of the fibre strand $\left(k_{\mathrm{w}}\right)$.

- A parametric study conducted with Abaqus/CAE confirms a strong influence of the geometric characteristics of the fibre strand on the resulting splitting forces in the concrete due to bond action.

- In addition to the conclusions drawn in [18], where the cross-sectional geometry of the fibre strand was identified as the main influencing parameter for the distribution of the splitting forces, an influence of the dominant direction of the regularly repeated cross-sectional variation was observed.

- Based on experimental and numerical data, a mechanical model is introduced which allows for an assessment of the magnitude and distribution of the splitting forces that occur when a single short fibre strand is pulled out of the concrete. This model is based on the theory of the tensile hoop stress developed for steel-reinforced structures decades ago [35], but also takes into account the non-uniform distribution of the tensile stresses in textile-reinforced concrete due to the influence of the cross-section geometry of the fibre strand (represented by parameter $k_{\mathrm{F}}$ ) and the dominant direction of the regularly repeating dimensional increase in the fibre strand (represented by parameter $k_{\mathrm{P}}$ )

\section{Outlook}

The broad range of experimental and numerical investigations carried out by the authors allows for the calculation of the splitting forces in textilereinforced concrete induced by fibre strands of category C (according to [21]). To estimate the cracking behaviour of textile-reinforced concrete, the focus must now shift to the influence of the concrete resistance. While studies to this respect have been carried out for CFRP tendons [36], so far no detailed investigations have been carried out for textile reinforcement. Further investigations on specimens with different concrete covers (and thus reinforcement ratio) and concrete qualities should therefore be carried out, and the fracture mechanics should be investigated in detail.

Acknowledgements The authors express their sincere gratitude to solidian $\mathrm{GmbH}$ for their ongoing support in the research on textile-reinforced concrete. The authors would also like to thank Dr Florian Rist from the Institute of Art and Design of TU Wien for his support in carrying out the optical measurements.

Authors' contributions Philipp Preinstorfer: Conceptualization, Methodology, Formal analysis, Investigation, Data Curation, Writing-Original Draft, Writing-Review and Editing, Visualization, Project administration. Benjamin Kromoser: Conceptualization, Supervision.

Funding Open access funding provided by TU Wien (TUW). No funding was received.

Data availability The data supporting the findings of this study are available from the corresponding author on request. Code availability The code of the parametric study will be available in the repository of the university.

\section{Compliance with ethical standards}

Conflict of interest The authors declare that they have no conflict of interest.

Open Access This article is licensed under a Creative Commons Attribution 4.0 International License, which permits use, sharing, adaptation, distribution and reproduction in any medium or format, as long as you give appropriate credit to the original author(s) and the source, provide a link to the Creative Commons licence, and indicate if changes were made. The images or other third party material in this article are included 
in the article's Creative Commons licence, unless indicated otherwise in a credit line to the material. If material is not included in the article's Creative Commons licence and your intended use is not permitted by statutory regulation or exceeds the permitted use, you will need to obtain permission directly from the copyright holder. To view a copy of this licence, visit http://creativecommons.org/licenses/by/4.0/.

\section{References}

1. Younes A, Seidel A, Rittner S, Cherif C, Thyroff R (2015) Innovative textile reinforcements for concrete applications. Beton-und Stahlbetonbau 110(S1):16-21. https://doi.org/ 10.1002/best.201400101

2. Schleser M (2008) Einsatz polymerimprägnierter, alkaliresistenter Glastextilien zur Bewehrung zementgebundener Matrices. Doctoral thesis, RWTH Aachen

3. Kirsten M, Freudenberg C, Cherif C (2015) Carbon Fibers, material of the 21st century. Beton- und Stahlbetonbau 110 (S1):8-15. https://doi.org/10.1002/best.201400105

4. Helbig T, Unterer K, Kulas C, Rempel S, Hegger J (2016) Pedestrian bridge made from carbon-concrete in AlbstadtEbingen-First entirely carbon-reinforced concrete bridge worldwide. Beton- und Stahlbetonbau 111(10):676-685. https://doi.org/10.1002/best.201600058

5. Scholzen A, Chudoba R, Hegger J (2015) Thin-walled shell structures made of textile-reinforced concrete. Struct Concr 16(1):106-114. https://doi.org/10.1002/suco. 201300071

6. Sharei E, Scholzen A, Hegger J, Chudoba R (2017) Structural behavior of a lightweight, textile-reinforced concrete barrel vault shell. Compos Struct 171:505-514. https://doi.org/10.1016/j.compstruct.2017.03.069

7. Brückner A, Ortlepp R, Curbach M (2006) Textile reinforced concrete for strengthening in bending and shear. Mater Struct 39(8):741-748. https://doi.org/10.1617/ s11527-005-9027-2

8. Herbrand M, Adam V, Kueres D, Hegger J (2017) Strengthening of existing bridge structures for shear and bending with carbon textile-reinforced mortar. Materials 10:1099. https://doi.org/10.3390/ma10091099

9. Schladitz F, Frenzel M, Ehlig D, Curbach M (2012) Bending load capacity of reinforced concrete slabs strengthened with textile reinforced concrete. Eng Struct 40:317-326. https://doi.org/10.1016/j.engstruct.2012.02. 029

10. Kromoser B, Preinstorfer P, Kollegger J (2019) Building lightweight structures with carbon-fiber-reinforced polymer-reinforced ultra-high-performance concrete: research approach, construction materials, and conceptual design of three building components. Struct Concr 20(2):730-744. https://doi.org/10.1002/suco.201700225

11. Krausmann F, Gingrich S, Eisenmenger N, Erb K-H, Haberl H, Fischer-Kowalski M (2009) Growth in global materials use, GDP and population during the 20th century. Ecol Econ 68(10):2696-2705. https://doi.org/10.1016/j. ecolecon.2009.05.007
12. Stoiber N, Hammerl M, Kromoser B (2020) Cradle-to-gate life cycle assessment of CFRP reinforcement for concrete structures: calculation basis and exemplary application. J Clean Prod. https://doi.org/10.1016/j.jclepro.2020. 124300

13. Kromoser B, Huber P, Preinstorfer P Experimental study of the shear load bearing behaviour of thin walled CFRP reinforced UHPC structures. In: FIB congress 2018-better, smarter, stronger, Melbourne, 2018, pp 364-365

14. Preinstorfer P, Kromoser B, Kollegger J (2019a) Flexural behaviour of filigree slab elements made of carbon reinforced UHPC. Constr Build Mater 199:416-423. https://doi.org/10.1016/j.conbuildmat.2018.12.027

15. Bielak J, Spelter A, Will N, Claßen M (2018) Anchorage behavior of textile reinforcement in thin concrete components. Beton- und Stahlbetonbau 113(7):515-524. https://doi.org/10.1002/best.201800013

16. Schütze E, Curbach M (2019) Experimental characterisation of the bond behaviour of carbon reinforced concrete with concrete splitting as significant failure mode. Bauingenieur 94(4): 133-141

17. Kulas C (2014) Zum Tragverhalten getränkter textiler Bewehrungselemente für Betonbauteile. doctoral thesis, RWTH Aachen

18. Preinstorfer P, Kromoser B, Kollegger J (2018) Influencing parameters on longitudinal cracking in textile reinforced concrete. Beton- und Stahlbetonbau 113(12):877-885. https://doi.org/10.1002/best.201800071

19. Lepenies IG (2007) Zur hierarchischen und simultanen Multi-Skalen-Analyse von Textilbeton. Doctoral thesis, TU Dresden

20. Preinstorfer P, Kollegger J (2020) New insights into the splitting failure of textile-reinforced concrete. Compos Struct 243:1-10. https://doi.org/10.1016/j.compstruct. 2020.112203

21. Preinstorfer P, Kromoser B, Kollegger J (2019b) Categorisation of the bond behaviour of textile reinforced concrete. Bauingenieur 94(11):416-424

22. Preinstorfer P, Pinzek A, Kollegger J (2020) Modellierung des Verankerungsverhaltens getränkter textiler Bewehrungen. Beton- und Stahlbetonbau 115(9):720-730. https://doi.org/10.1002/best.202000011

23. Preinstorfer P (2020) Zur Spaltrissbildung von textilbewehrtem Beton. TU Wien Academic Press, Vienna. https://doi.org/10.34727/2020/isbn.978-3-85448-034-1

24. Beßling M, Orlowsky J (2019) Investigations on the bond behaviour of textiles with various coatings in TRC. In: Proceedings of the fib Symposium 2019: Concrete-Innovations in Materials, Design and Structures, Kraków, Poland, pp 212-219

25. Lorenz E (2014) Endverankerung und Übergreifung textiler Bewehrungen in Betonmatrices. Doctoral thesis, TU Dresden

26. Lorenz E, Ortlepp R, Hausding J, Cherif C (2011) Efficiency increase of textile reinforced concrete by use of textile reinforcements from the extended warp knitting process. Beton-und Stahlbetonbau 106(1):21-30. https://doi.org/10.1002/best.201000072

27. Li Y, Bielak J, Hegger J, Chudoba R (2018) An incremental inverse analysis procedure for identification of bond-slip laws in composites applied to textile reinforced 
concrete. Compos B Eng 137:111-122. https://doi.org/10. 1016/j.compositesb.2017.11.014

28. Lorenz E, Schütze E, Schladitz F, Curbach M (2013) Textile reinforced concrete-overview of standard test methods. Beton- und Stahlbetonbau 108(10):711-722. https://doi.org/10.1002/best.201300041

29. Austrian Standards Institute (ON) (2015) ÖNORM EN 1992-1-1. Eurocode 2: Design of concrete structures-Part 1-1: General rules and rules for buildings. Vienna

30. Hillerborg A, Modéer M, Petersson PE (1976) Analysis of crack formation and crack growth in concrete by means of fracture mechanics and finite elements. Cem Concr Res 6 (6):773-781. https://doi.org/10.1016/0008-8846(76)900077

31. Lubliner J, Oliver J, Oller S, Oñate E (1989) A plasticdamage model for concrete. Int J Solids Struct 25(3):299326. https://doi.org/10.1016/0020-7683(89)90050-4

32. Misra RK, Dixit A, Mali HS (2014) Finite element (FE) shear modeling of woven fabric textile composite. Proc
Mater Sci 6:1344-1350. https://doi.org/10.1016/j.mspro. 2014.07.113

33. Ng S-P, Tse P-C, Lau K-J (1998) Numerical and experimental determination of in-plane elastic properties of $2 / 2$ twill weave fabric composites. Compos B Eng 29(6):735744. https://doi.org/10.1016/S1359-8368(98)00025-0

34. Krüger M (2004) Vorgespannter textilbewehrter Beton. doctoral thesis, Universität Stuttgart

35. Tepfers R (1979) Cracking of concrete cover along anchored deformed reinforcing bars. Mag Concr Res 31 (106):3-12. https://doi.org/10.1680/macr.1979.31.106.3

36. Stark A, Classen M, Hegger J (2019) Bond behaviour of CFRP tendons in UHPFRC. Eng Struct 178:148-161. https://doi.org/10.1016/j.engstruct.2018.10.002

Publisher's Note Springer Nature remains neutral with regard to jurisdictional claims in published maps and institutional affiliations. 